\title{
MELLON INSTITUTE
}

\section{REPORT FOR 1958-59}

$\mathrm{T}$ HE annual report of the chairman, M. B. Ridgway, to the Board of Trustees of the Mellon Institute for the year ended February 28, 1959, records an increase in the Institute's independent research staff from 22 to 56 , while a further 254 scientists and their assistants were engaged on the 47 industrially sponsored applied science fellowships and projects at the close of the year (Scientific Research in Mellon Institute 1958-1959. Pp. $x+38$. Pittsburgh : Mellon Institute, 1959). A plan was developed for industrial affiliation with the fundamental research sector of the Institute's programme whereby co-operation can contribute to the support of fundamental research in a designated area.

During the year the independent research programme embraced studies of some of the properties of a group of esterases, with special reference to the cholinesterase of human blood plasma. A rapid ultravielet spectrophotometric method was developed for the assay of hydrolysis of certain substrates and evidence obtained that promotion of enzyme activity depends partly upon a competition between the activator and the substrate for a negatively charged site on the enzyme. Studies of fibrogenesis in collagen solution were undertaken to explore the spatial arrangement of the protein amino groups which are regarded as responsible for the characteristic bands observed in collagen fibrils with the electron microscope. Investigations continued on the mechanism of enzymatic hydroxylation and on the chemical structures of two metabolites of $p$-aminobenzoic acid.

In inorganic chemistry the relatively little-known chemistry of osmium was studied, and besides the discovery of univalent osmium evidence for a zero-valent osmium complex was obtained. For studies of the magnetic properties of transition metal compounds a magnetic susceptibility balance was set up, utilizing a 'Varian' 4-in. electromagnet and a vacuum microbalance. A further programme is concerned with the formation, reactions and structures of inorganic species containing cation-oxygen, cationhydroxyl and cation-water linkages, while studies in the chemistry and physics of natural and synthetic macromolecular substances continued to develop. The contribution of the chain configuration to the internal energy of a polymer has been determined from the dependence on temperature of the stress of the cross-linked polymer. This occurs when stretched in the amorphous state, and for polyethylene and polyisobutylene this energy effect can be correlated with independently estimated energy differences between the principal bond conformations. Stresstemperature measurements on fibres prepared from muscle by extraction and chemical cross-linking can be satisfactorily interpreted as due to reversible melting and crystallization processes. Studies on branched-chain polymers have sought to synthesize molecules of precisely known structure and to correlate their physical properties with the chain architecture. These included a theoretical analysis of the distribution of molecular weight resulting from the formation of branohed molecules, while investigation of the statistical thermodynamics of dilute polymer solutions continued. A theoretical study of the diffraction pattern of a crystal containing a single dislocation indicates that it is doubtful whether or not double-crystal spectrometer measurements can be used to obtain dislocation densities from first principles.

In the fields of organic chemistry the structure of the alkaloid skytanthine has been firmly established by a combination of classical degradation and instrumental methods. The existence in cyclic sulphite esters of a stereoisomerism arising from the noncoplanarity of the sulphite group has been demonstrated by a nuclear magnetic resonance method. The kinetics of the dehydrohalogenation and rearrangement of $1: 1$-diarylhalogenoethylenes have been studied and also the possible extension of the reaction to purely aliphatic and alicyclic systems. Installation of a 'Varian' dual-purpose nuclear magnetic resonance spectrometer operating at 60 Mc./s. has greatly assisted the solution of many organic analytical problems. From July 1, 1958, the half-time responsibility for service research in the Institute's former Department of Research in Chemical Physics was transferred to the newly established Research Services. High-resolution infrared absorption measurements have been conducted by the matrix isolation technique at temperatures as low as $4.2^{\circ} \mathrm{K}$. on the photolysis products of ammonia, $1: 2$-diazine and azomethane; survey spectra of about 150 inorganic salts containing poly. atomic ions have been obtained in the cæsium bromide region (700-300 cm.-1) using a special long wavelength infra-red spectrometer and a Raman apparatus with red excitation. Crystal diffraction studies of simple organo-silicon compounds are being pursued; the structure of dicobalt octacarbonyl is under investigation for information about the bonding of the cobalt atoms, while new relations between thermodynamics and continuum mechanics have been revealed in an investigation of the axiomatization of thermodynamics. Current studies in radiation research include the radiation decomposition of hydrocarbons, using gas chromatography for analysis, the kinetics of photochemically produced free radicals and the radiation-induced cross-linking of polymers in solution. During the year five fellows were appointed in organic chemistry.

Fellowship investigations under 'metals programme' include the thermodynamics of systems of importance to the steelmaker, a long-range research and development programme to evaluate ferrous alloys for high strength, particularly at high temperatures, and the physical metallurgy of semi-conductor devices. Continued attention was given by the Artists' Materials Fellowship to the fading of pigments and loss of solubility of varnishes in light. The chemical hygiene fellowship is giving increased attention to the safety of food additives. Under the water pollution abatement fellowship a paper chromatographic technique has been developed for determining fatty acids in water, and a continuous counter-current extractor is being used to recover soluble organic matter from river water. Under the organic synthesis fellowship, heterocyclic derivatives, such as imidazolines, hexa. hydropyrimidines and perhydrotriazones, which give excellent crease resistance to cotton, have been 
prepared; the study of emulsion paints comprising homo- and co-polymer systems has indicated a correlation between water-resistance, hardness and flexibility of latex films, and polymer composition; and the investigation of polyethers from polyols and propylene oxide has assisted the rapid growth of the polyurethane foam industry. Both the coal chemicals fellowship and the petroleum fellowship

\section{LABOUR TURNOVER}

$\mathrm{L}$ ABOUR turnover has been a subject of inquiry and discussion since interest was first focused on the problem during the First World War. It is commonly regarded as a source of serious economic waste. The level of turnover in a firm is often regarded as an index of morale among the employees.

Research workers have attempted to analyse the causes of labour turnover by relating it to different groups of factors. The most important of the external factors are the level of employment and the availability of alternative work. The internal factors are the composition of the labour force itself, that is to say, whether men or women are employed, whether they are skilled or unskilled; the length of time workerg have been employed, their age and the location of their homes. Wage rates, hours and conditions of work and the personal relationships existing within a firm may also have important effects on labour turnover.

The findings of research do not appear to have helped mansgements very much in their efforts to reduce labour turnover. The British Institute of Management survey of 1949 and 1950, covering approximately two hundred companies, showed annual labour turnover rates varying from 13 per cent to 59 per cent for men and from 24 per cent to 75 per cent for women per annum. These are industry rates. Individual companies fluctuated below and above this range. Labour turnover was calculated on the basis of :

Number of leavers in period under review Average number of persons employed during same period

Commonly agreed facts about labour turnover are that in any given period it is heavier among shortservice employees than among those of longer service and that much of it does not represent true mobility but, from the social point of view, useless changes from one job to another.

What has not been established is to what extent labour turnover matters to the individual company and to society and the extent to which labour turnover can be measured in financial terms or whether its effects are largely intangible and in any event non-financial.

Excessive labour turnover is assumed to cause waste and inefficiency. Few studies have attempted to find out what exactly is the extent of this waste. One of the drawbacks is the difficulty of measurement. The effects of labour turnover are widespread and varied and attempts to assess them in financial terms can easily become either over-simplified or over-imaginative and remote from verifiable facts.

An appraisal of the importance of labour turnover to industry cannot be complete unless there is some estimate of its financial effects. Certain effects as, cover a wide field and, under the power rectifier fellowship, laboratory development of the first new power rectifier was completed and the growth of highly perfect single crystals of silicon and germanium has been studied. New organosilicon compounds, monomers and polymers have been prepared under the silicones fellowship, including some hybrid organotin organosiloxane compounds. for example, the impact on the morale of the working group of a continually changing labour force, cannot be assessed in financial terms. The more tangible costs are also important.

What has been noeded is a series of published case-studies of the experience and of the financial cost of labour in individual concerns. The British Institute of Management has now published a series of sixteen such studies*. The studies have been of the cost of labour turnover among direct production workers. No studies have been undertaken among clerical or selling staff.

The data provided by these case-studies and by supplementary information obtained from a large number of firms show that :

(1) In five out of sixteen studies, labour turnover was adding $10 \mathrm{~s}$. or more per week to the wage cost of each individual employed.

(2) The main factors which appear to affect labour turnover cost are the impact of learners on production, the extent to which saleable production is lost through labour turnover and the methods used to make up production losses.

(3) The amount spent on training, induction and interviewing is a matter of company policy and will naturally affect the level of its labour turnover cost. Money spent in this way, however, has a constructive result and is not waste, as is the cost arising from other categories.

(4) Labour turnover has certain long-term effects which are not measurable in financial terms. Most important of these are the effect of high labour turnover on the morale of the work force, the wear and tear on supervisory staff and the loss of customer's' goodwill by failure to fulfil orders and to meet delivery dates. To combat these effects by reducing labour turnover, it seems worth spending money on training, induction and interviewing.

(5) Labour turnover appears to be most costly in those firms where there is a high proportion of semiskilled jobs peculiar to the company itself. This is because the training period is often long and it is rare to find new employees with experience of similar work. The recognized skilled occupations and the relatively unskilled ones, for example, labouring and cleaning, do not involve companies in high training costs.

(6) The results of the inquiry as a whole suggest that keeping labour turnover low may be a relatively expensive business, almost as expensive as allowing it to increase with consequent increased production costs and sales losses. The decision about how much to spend on redueing labour turnover must be based not only on the figures of tangible waste but also on management's estimate of the seriousness of the non-financial aspects.

T. H. HAWKINS

" "Cost of Labour Turnover", 17s. $6 d$. 